\title{
Preferences for fresh tomatoes with a focus on young consumers in Germany - Choice-experiment and latent class
} analysis

\author{
K. Jürkenbeck and S.G.H. Meyerding
}

University of Goettingen, Department of Agricultural Economics and Rural Development, Marketing of Food and Agricultural Products, Göttingen, Germany

\section{Summary}

Knowledge about different types of tomato consumers and what consumers are looking for when purchasing tomatoes is scarce. This study focuses on fresh market tomatoes and their consumers, with the objective to identify homogenous target groups of tomato consumers. The purchase situation was simulated through a choice-experiment, and the data was analysed using latent class analysis. The sample consisted of 337 consumers from Germany, and the survey was conducted in April and May 2017. Most of the participants $(65.2 \%)$ were in the age class from 20 to 29 years. Female consumers accounted for $65 \%$ of the sample. Based on the results of the latent class analysis, there were three different types of consumers, with a membership probability of $91.3 \%$. For each class, the preferred attributes, the price preferences and the favoured food-related lifestyles were estimated. We identified three different types of tomato consumers, namely price-sensitive, extrinsic-sensitive and intrinsic-sensitive consumers. Each class differently valued the tomato attributes. The presented information helps growers, breeders as well as marketing practitioners to gain insights into the attributes consumers are looking for when purchasing tomatoes.
\end{abstract}

Keywords

food-related lifestyle, labels, local food, part-worth utility, regional, sustainability

\section{Introduction}

There are numerous studies on sensory analysis concerning tomato preferences (e.g., Fernqvist and Hunter, 2012; Hongsoongnern, 2007; Oltman et al., 2016; Pagliarini and Monteleno, 2001; Sinesio et al., 2007; Sinesio et al., 2010). From a consumer's point of view, however, other attributes might also play an important role in their purchase behaviour. Some people, for example, might prefer a regional product, and therefore, their evoked set is different from that of consumers who are price-conscious.

This study looks at consumers' preferences of specific characteristics of tomatoes. It focuses on the attributes colour, size, inner firmness, taste, aroma, consistency, regionality, label and price, which are important based on the reviewed literature (Adeoye et al., 2015; Causse et al., 2010; Oltman et al., 2014). The implicit assumptions of these attri-

\section{Significance of this study}

What is already known on this subject?

- Consumers are dissatisfied with the taste of the tomato because scientists have focused on factors such as long shelf-life.

What are the new findings?

- The present study identified three target groups; each group prefers different attributes of a fresh tomato.

What is the expected impact on horticulture?

- Knowledge about consumer preferences when purchasing tomatoes can help breeders, growers and the marketing industry to more efficiently market tomatoes.

butes are that respondents value the attributes differently, which is reflected in their buying behaviour.

In this context, the objective of this study is to obtain deeper insights into young German consumers' preferences when purchasing fresh tomatoes. Young consumers are defined as citizens who are not permanently settled yet and/ or not permanently in the labour market and who have no family or children (Keller et al., 2017). It is important to understand which product attributes young consumers prefer in order to know which products they will purchase in the future, as they will govern the future market of retail companies.

The study addresses the following questions: Are there different consumer segments in terms of tomato attributes? If yes, how do these groups differ among each other? Which attributes obtain the highest consumer attention?

One way to simulate a purchase situation is an experiment. A discrete choice-experiment depicts the purchase situation in a supermarket, when the consumer has to decide between different product variations. In this study, 337 consumers performed a discrete choice-experiment. The random utility theory assumes that people choose what they prefer and do not choose what they do not like. In a choice-experiment, the respondents had to choose the type of tomato they would like to purchase.

Thus, it is useful to determine the utility of the different product attributes. The main objective of a latent class analysis is to uncover relationships among data when some variables are unobserved. Additionally, we cannot include all attributes in the study, as this would be beyond the scope of this research. Against this background, latent class analysis 
was applied, which uncovers the latent variables of the consumers and allocates them into classes. This way, we can obtain homogenous target groups.

This study is novel for two reasons: First, we identified three classes of young tomato consumers and provide specific insights into their preferred tomato attributes. Second, we used food-related lifestyle statements to characterise the eating habits and the overall behaviour of the three consumer classes in the context of food.

\section{Materials and methods}

The conjoint analysis, where consumer utilities are based on separate utilities for product attributes, has been developed by Lancaster (1966). Choice-experiments are being widely used to measure consumer preferences, consumer segmentation and the willingness to pay for a product (Carroll et al., 2013; Skreli and Imami, 2012). In the choice-experiment, tomatoes were used as a product example because they are a widely used vegetable for cooking and are widely cultivated in Germany and numerous other countries.

\section{Survey design}

The presented choice-experiment includes a survey with 15 choice sets, where the respondent had to choose one out of three alternatives. The design of the choice-experiment was developed with the software package Lighthouse Studio 9.3. A choice-experiment was performed because it is a wellknown method to predict consumer preferences for products which are in the development stage and not launched yet (Auspurg and Liebe, 2011). Additionally, a choice-experiment resembles the decision-making in an actual supermarket. In the current study, the participants had to choose one of the product alternatives. We selected nine attributes for the choice-based conjoint analysis, resembling key drivers of the buying decision for tomatoes. All attributes and the respective levels are based on literature research (Adeoye et al., 2015; Causse et al., 2010; Oltman et al., 2016) and are shown in Table 1.

The respondents also had to answer questions about their sociodemographic background, e.g., gender, age, marital status, number of persons living in the household and monthly net household income. This information can help to better understand the sample and to give advice to young consumers. Besides, participants had to provide information about their tomato preferences, such as the frequency of eating fresh tomatoes, the place of purchase, tomato usage, the use of home-grown tomatoes, tomato storage and preferred tomato varieties; these data were used to describe the sample in more detail. Additionally, the respondents had to estimate the relevance of different product features and food-related lifestyles (Thøgersen, 2017) on a Likert scale. The lifestyle statements were used to precisely describe the different consumer classes. The survey was pre-tested by academics to ensure that consumers will understand the different tomato attributes; the results were integrated in the final survey.

\section{Data analysis}

Statistical data analysis (descriptive statistics) was carried out using the software package SPSS, version 24, while latent class analysis and part-worth utility estimation were performed using the software Lighthouse Studio 9.3, from Sawtooth Software.

Latent class analysis assumes that the utility the respondents draw from an attribute is individual-specific and builds
TABLE 1. Attribute levels of the choice-experiment.

\begin{tabular}{ll}
\hline Attributes & Attribute levels \\
\hline Colour & Red \\
& Orange \\
& Yellow \\
& Green \\
\hline Size & Small \\
& Medium \\
& Large \\
\hline Inner firmness & Firm \\
& Soft \\
\hline Taste & Sweet \\
& Sour \\
& Fruity \\
\hline Aroma & Very intense tomato taste \\
& Intense tomato taste \\
& Tomato taste \\
\hline Consistency & Juicy \\
& Mealy \\
& Crispy \\
\hline Regionality & My city \\
& The surrounding of my city \\
& My state \\
& Germany \\
& Organic \\
& From my region \\
& Fair Trade \\
& Pro Planet \\
& Without gene technology \\
& Climate \\
\hline Label & 1.49 \\
& 1.79 \\
& 2.09 \\
& 2.39 \\
& 2.69 \\
& 2.99 \\
& \\
& \\
& \\
&
\end{tabular}

Source: own representation.

Note: Pro planet is a retailer-specific label in Germany to ensure ecological and social sustainability.

upon the unobservable class membership, which depends on the individual's choices (Greene and Hensher, 2003). In this study, we wanted to uncover the tomato attributes most relevant for young consumers, who drive decision-making in the purchase situation. Therefore, latent class analysis was used to identify different segments of consumer preferences for fresh market tomatoes.

\section{Results and discussion}

\section{Sample description}

In total, 337 participants answered the online questionnaire; they did not get any compensation. The majority, i.e., $65 \%$, of the respondents was female. Besides that, $78.9 \%$ of the respondents were single and living in one- and two-person households. The average monthly net household income of all respondents was between less than $501 €(27.3 \%)$ and 
TABLE 2. Sample description $(N=337)$.

\begin{tabular}{llrr}
\hline Characteristics & Characteristic specifications & Sample (\%) & ${\text { German population }(\%)^{*}}^{*}$ \\
\hline Gender & Female & 65.0 & 50.9 \\
\hline Age & $18-19$ & 35.0 & 49.1 \\
\hline & $20-29$ & 12.8 & 2.3 \\
& $30-39$ & 65.0 & 11.8 \\
& $40-49$ & 5.3 & 11.8 \\
& $50-59$ & 2.1 & 16.6 \\
& $60-69$ & 10.7 & 15.4 \\
& $70+$ & 3.3 & 9.1 \\
\hline Educational level & Not finished & 0.6 & 16.3 \\
& Apprenticeship & 11.3 & 3.6 \\
& Technical/specialist degree & 19.6 & 48.5 \\
& Bachelor's degree & 29.4 & 29.5 \\
& Master's degree & 16.3 & 1.5 \\
& PhD & 9.5 & 1.0 \\
& Other & 2.4 & 1.1 \\
\hline Single & 11.6 & 14.8 \\
\hline & Engaged & 78.9 & 39.9 \\
& Married & 3.0 & - \\
& Separated & 14.5 & 45.8 \\
& Widowed & 2.4 & 7.1 \\
\hline
\end{tabular}

Source: *Statistisches Bundesamt 2016, own calculations.

between $501 €$ and $1,000 €(27.0 \%)$. Additionally, the majority $(40.7 \%)$ consumed tomatoes once to twice a week and purchased them mainly in the supermarket, followed by discount stores, wholefood shops, weekly markets, organic food stores and farmers shops. Seventy-eight percent of the respondents used tomatoes in a salad, followed by using tomatoes for cooking, as a snack, on a sandwich as well as in other situations (multiple responses). Of the respondents, 50.7\% grew their own vegetables, and $25.5 \%$ grew tomatoes. Most respondents, namely $56.1 \%$, stored tomatoes in the fridge, which results in a loss of aroma and taste. It should be noted that our sample is not representative of the German population, as it was a convenience sample. The link to the website of the survey was given to university students who in turn forwarded it to their social environment. Table 2 provides the socio-demographic characteristics of the sample.

\section{Latent class analysis}

There are numerous different criteria to choose the optimal number of classes in latent class analysis, including the Consistent Akaike Information Criterion (CAIC), the Bayesian Information Criterion (BIC), the Akaike Information Criterion (AIC) and Percent Certainty (Pct Cert). In this study, AIC and BIC were used to choose the optimal number of classes because they seem to be superior to the other methods (Nylund, 2007). Overall, the results indicate that three classes matched better than the solutions with two, four or five classes, shown in Table 3. The values of AIC and BIC decreased substantially up to class 3 , while the subsequent decrease was less significant. The values of the selection criteria are shown in Table 3.

\section{Relative attribute importance}

To segment the market, companies are interested in knowing which attribute is important for each class.

Class 1 was the smallest cohort and accounted for $28.5 \%$ of the sample. The most important attribute was price (26.2\%), followed by colour (21.2\%), while size (4.7\%) and inner firmness $(0.02 \%)$ were the least important attributes. Because price was the most important attribute, this class can be termed "price-sensitive consumers". They prefer tomatoes with the attribute levels red, medium, soft, fruity and organic. They have the highest preference for a price of $1.49 €$ for $500 \mathrm{~g}$ of fresh tomatoes, while the other two segments have the highest part-worth utilities for a price of $1.79 €$ and $2.09 €$, respectively. It can be assumed that this class is likely to purchase fewer tomatoes when the price increases.

Class 2 accounted for $33.2 \%$ of the sample and valued co-

TABLE 3. Summary of model selection.

\begin{tabular}{lccccc}
\hline Classes & Replication & Pct Cert. & AIC & CAIC & BIC \\
\hline 1 & 2 & 21.14670 & 8810.21205 & 9005.94352 & 8979.94352 \\
2 & 9 & 26.12055 & 8311.76902 & 8710.76008 & 8657.76008 \\
3 & 17 & 28.38143 & 8114.65346 & 8716.90411 & 8636.90411 \\
4 & 14 & 29.64104 & 8028.74825 & 8834.25850 & 8727.25850 \\
5 & 8 & 30.62911 & 7973.00389 & 8981.77373 & 8847.77373 \\
\hline
\end{tabular}

Source: own calculations. 
TABLE 4. Results of the latent class logit model with ANOVA results.

\begin{tabular}{|c|c|c|c|}
\hline \multirow[t]{2}{*}{ Class size } & $\begin{array}{l}\text { Price-sensitive consumers } \\
\qquad 28.5 \% \\
\end{array}$ & $\begin{array}{l}\text { Extrinsic-sensitive consumers } \\
33.2 \%\end{array}$ & $\begin{array}{c}\text { Intrinsic-sensitive consumers } \\
38.4 \% \\
\end{array}$ \\
\hline & \multicolumn{3}{|c|}{ Attribute importance (\%) } \\
\hline Colour & $21.23^{a}$ & $51.13^{b}$ & $12.74^{c}$ \\
\hline Size $e^{* * *}$ & $4.75^{\mathrm{a}}$ & $3.03^{a}$ & $2.03^{b}$ \\
\hline Inner firmness ${ }^{\star * *}$ & $0.02^{\mathrm{a}}$ & $2.21^{a}$ & $8.78^{b}$ \\
\hline Taste $^{\star \star *}$ & $13.24^{a}$ & $11.58^{b}$ & $17.62^{\mathrm{a}}$ \\
\hline Aroma*** & $5.42^{\mathrm{a}}$ & $3.86^{b}$ & $6.65^{a}$ \\
\hline Consistency $^{* * *}$ & $11.51^{\mathrm{a}}$ & $11.07^{\mathrm{a}}$ & $39.41^{b}$ \\
\hline Regionality*** & $8.56^{a}$ & $2.29 \mathrm{~b}$ & $2.03^{b}$ \\
\hline Label ${ }^{* \star *}$ & $8.98^{a}$ & $3.42^{b}$ & $2.57^{\mathrm{b}}$ \\
\hline Price ${ }^{* \star *}$ & $26.28^{a}$ & $11.39^{b}$ & $8.17^{\mathrm{b}}$ \\
\hline
\end{tabular}

Notes: different letters a, b, c signify a significant $(p<0.05)$ difference between groups according to Tukey, Dunnett-T and Games-Howell 0.05 ; ${ }^{* * *} p<0.001$.

TABLE 5. Part-worth utilities for each attribute and level.

\begin{tabular}{|c|c|c|c|c|}
\hline Attributes & Levels & $\begin{array}{c}\text { Price-sensitive } \\
\text { consumers }\end{array}$ & $\begin{array}{c}\text { Extrinsic-sensitive } \\
\text { consumers }\end{array}$ & $\begin{array}{l}\text { Intrinsic-sensitive } \\
\text { consumers }\end{array}$ \\
\hline \multirow[t]{4}{*}{ Colour } & Red & 69.54 & 237.11 & 51.84 \\
\hline & Orange & 49.21 & 118.03 & 12.51 \\
\hline & Yellow & 2.79 & -132.06 & -1.55 \\
\hline & Green & -121.54 & -223.08 & -62.79 \\
\hline \multirow[t]{3}{*}{ Size } & Large & -3.78 & 15.75 & -1.91 \\
\hline & Medium & 23.27 & -11.55 & -8.19 \\
\hline & Small & -19.49 & -4.19 & 10.10 \\
\hline \multirow[t]{2}{*}{ Inner firmness } & Firm & -0.07 & 9.96 & 39.51 \\
\hline & Soft & 0.068 & -9.96 & -39.51 \\
\hline \multirow[t]{3}{*}{ Taste } & Sweet & 31.33 & 44.76 & 46.74 \\
\hline & Sour & -75.26 & -59.48 & -102.65 \\
\hline & Fruity & 43.93 & 14.72 & 55.91 \\
\hline \multirow[t]{3}{*}{ Aroma } & Very intense tomato taste & 20.50 & 20.83 & 24.29 \\
\hline & Intense tomato taste & 7.76 & -13.94 & 11.28 \\
\hline & Tomato taste & -28.26 & -6.89 & -35.57 \\
\hline \multirow[t]{3}{*}{ Consistency } & Juicy & 31.87 & 32.79 & 104.29 \\
\hline & Mealy & -67.75 & -66.22 & -229.48 \\
\hline & Crispy & 35.88 & 33.43 & 125.19 \\
\hline \multirow[t]{4}{*}{ Regionality } & My city & 13.76 & 0.21 & 6.43 \\
\hline & The surrounding of my city & 33.34 & 9.72 & -5.84 \\
\hline & My state & -3.36 & 0.99 & 8.84 \\
\hline & Germany & -43.74 & -10.92 & -9.44 \\
\hline \multirow[t]{6}{*}{ Label } & Organic & 38.65 & 14.95 & 7.88 \\
\hline & From my region & -7.61 & -11.28 & 15.44 \\
\hline & Fair Trade & 18.97 & 19.54 & -6.69 \\
\hline & Pro Planet & -42.16 & -7.62 & -7.04 \\
\hline & Without gene technology & 0.91 & -7.69 & -1.90 \\
\hline & Climate & -8.75 & -7.89 & -7.69 \\
\hline \multirow[t]{7}{*}{ Price } & $1.49 €$ & 91.91 & -3.39 & 12.16 \\
\hline & $1.79 €$ & 68.21 & 47.44 & 7.52 \\
\hline & $2.09 €$ & 44.41 & 2.52 & 29.98 \\
\hline & $2.39 €$ & -6.60 & 18.03 & -6.18 \\
\hline & $2.69 €$ & -6.13 & 21.17 & -5.96 \\
\hline & $2.99 €$ & -47.15 & -30.74 & 6.05 \\
\hline & $3.29 €$ & -144.64 & -55.02 & -43.58 \\
\hline
\end{tabular}

Source: own calculations. Note: Pro planet is a retailer-specific label in Germany to ensure ecological and social sustainability. 
lour $(51.1 \%)$ as most important attribute, while regionality $(2.29 \%)$ and inner firmness $(2.21 \%)$ were least important. They can be termed "extrinsic-sensitive consumers", because they care about the colour of the tomato. This cohort had the strongest preference for colour among the three classes. When purchasing tomatoes, they generally look for red, large, firm, sweet and fair trade tomatoes.

Class 3 had a strong preference for consistency and taste, of which consistency is related to the texture of the tomato. Earlier research has shown that tomato texture is an important aspect for consumers (Causse et al., 2003). The values for consistency were the highest among the three classes. Class 3 accounted for $38.4 \%$ of the respondents and was therefore the largest class. Respondents of this class did not value attributes such as label (2.57\%), regionality (2.03\%) and size $(2.03 \%)$, but rather valued intrinsic attributes. This group was therefore labelled "intrinsic-sensitive consumers". On average, this cohort had the highest preference for a price of $2.09 €$ for $500 \mathrm{~g}$ of fresh tomatoes. They preferred fruits which are red, small, firm, fruity, and originate from the respective region. It can be assumed that this class values food quality higher than price and might even purchase more expensive tomatoes because they believe that they are of a better quality. The results of the conjoint analysis are shown in Table 4.

\section{Part-worth utilities}

To obtain a deeper understanding of the segment preferences, the part-worth utilities advise which levels of the attributes are important to each class; the results are shown in Table 5.

All classes had a high preference for red tomatoes with a very intensive tomato taste and a crispy consistency. The finding that colour and crispy consistency are important attributes is consistent with prior research (Oltman et al., 2014; Pagliarini et al., 2001). Besides that, recent research states that flavour is an attractive tomato attribute (Oltman et al., 2014; Oltman et al., 2016). Literature regarding consumer preference in terms of tomato size is rare, and the results of the latent class analysis show that there is no clear preference for one specific tomato size. Each class preferred another size (small, medium and large), and these results are not consistent with earlier study results which state that moderately sized tomatoes, such as the size of a baseball, are preferred (Oltman et al., 2014). In our study, tomatoes of a baseball size were classified as large.

Regarding the preference of the other researched attributes, the three classes differed. Class 1 has a high preference for a medium-sized tomato with a fruity taste and preferred fruits which were organically grown in their region. Research shows that the organic market in Germany has grown, and therefore, the awareness of an organic label is high (Meyerding, 2016). The price of $1.49 €$ per $500 \mathrm{~g}$ achieved the highest value among all attributes and levels. Class $2 \mathrm{had}$ a higher preference for large tomatoes with a sweet taste and preferred fair-trade tomatoes which were grown in the surroundings of their city. The fair trade label is a well-established label and trusted by consumers (Meyerding, 2016). It is therefore not surprising that class 2 preferred tomatoes labelled as fair trade, although such tomatoes are only rarely available on the German market. This group had the highest preference for a price of $1.79 €$ per $500 \mathrm{~g}$. Class 3 had a high preference for small tomatoes with a fruity taste; these respondents preferred regionally grown tomatoes and showed the highest path-worth utility for the price of $2.09 €$ per $500 \mathrm{~g}$.

\section{Analysis of variance}

To test whether the three classes were statistically significantly different in terms of the attributes which were used in the choice-experiment, purchase place and overall satisfaction, analysis of variance was used. When the ANOVA $p$-value was significant, the post hoc tests Tukey, Games-Howell and Dunnett-T (two-tailed) were performed to find out which groups differed. As a threshold for significance, a $p$-value less than 0.05 was used. The results for the ANOVA were obtained from the direct questions about the attributes as well as from the questions about tomato consumption; they are summarised in Table 6.

Colour and size were most important for extrinsic-sensitive consumers. Based on our results, this group was significantly different at a $p$-level of 0.01 . Intrinsic-sensitive consumers valued inner firmness as well as taste, and the differences between the classes regarding inner firmness were

TABLE 6. ANOVA results from direct questions.

\begin{tabular}{|c|c|c|c|c|c|c|c|}
\hline \multirow[t]{2}{*}{ Variable } & \multicolumn{2}{|c|}{$\begin{array}{c}\text { Price-sensitive } \\
\text { consumers }\end{array}$} & \multicolumn{2}{|c|}{$\begin{array}{c}\text { Extrinsic-sensitive } \\
\text { consumers }\end{array}$} & \multicolumn{2}{|c|}{$\begin{array}{l}\text { Intrinsic-sensitive } \\
\text { consumers }\end{array}$} & \multirow[t]{2}{*}{$p$-value } \\
\hline & Mean & Std. Dev. & Mean & Std. Dev. & Mean & Std. Dev. & \\
\hline Colour & $3.44^{a}$ & 0.949 & $4.27^{b}$ & 0.900 & $3.56^{a}$ & 0.927 & 0.000 \\
\hline Size & $2.73^{a}$ & 0.968 & $3.13^{b}$ & 0.931 & $0.09 a$ & 2.950 & 0.003 \\
\hline Inner firmness & $3.54^{a}$ & 0.939 & $3.17^{a}$ & 0.801 & $3.98^{b}$ & 0.751 & 0.000 \\
\hline Taste & $4.38^{a}$ & 0.884 & $4.59^{a, b}$ & 0.512 & $4.63^{b}$ & 0.735 & 0.026 \\
\hline Aroma & $4.04^{a}$ & 0.884 & $4.21^{a, b}$ & 0.686 & $4.36^{b}$ & 0.773 & 0.012 \\
\hline Consistency & $3.91^{\mathrm{a}}$ & 0.855 & $3.99 \mathrm{a}, \mathrm{b}$ & 0.717 & $4.17^{b}$ & 0.821 & 0.049 \\
\hline Regionality & 3.25 & 1.039 & 3.05 & 0.985 & 3.15 & 0.992 & 0.387 \\
\hline Label & 2.48 & 1.129 & 2.32 & 0.970 & 2.22 & 0.902 & 0.145 \\
\hline Price & 3.14 & 0.948 & 3.17 & 0.948 & 2.98 & 0.842 & 0.217 \\
\hline Discounter & $0.56^{a}$ & 0.499 & $0.43^{a, b}$ & 0.497 & $0.35^{b}$ & 0.478 & 0.007 \\
\hline Weekly market & $0.09 a$ & 0.282 & $0.13^{a, b}$ & 0.342 & $0.23^{b}$ & 0.426 & 0.008 \\
\hline Satisfaction with tomato taste & $3.35^{\mathrm{a}}$ & 1.080 & $3.72^{b}$ & 0.922 & $3.51^{a, b}$ & 0.912 & 0.026 \\
\hline
\end{tabular}

Different letters $a$, b signify a significant $(p<0.05)$ difference between groups according to Tukey, Dunnett-T and Games-Howell 0.05.

Scale of the attributes ranges from $1=$ very unimportant to $5=$ very important; satisfaction with tomato taste scale ranges from $1=$ do not agree at all to $5=$ totally agree. 
significant at a $p$-level of 0.01 , while taste was significant at a $p$-level of 0.05. Moreover, intrinsic-sensitive consumers highly valued the aroma of the tomato. Regarding this attribute, the groups differed significantly at a $p$-level of 0.05 . These differences among the three classes regarding the tomato attributes are consistent with the differences of the findings of the latent class analysis. Price-sensitive consumers are most likely to purchase their tomatoes in a discounter, followed by extrinsic-sensitive and intrinsic-sensitive consumers ( $p$-value is significant at a level of 0.01 ). Intrinsic-sensitive consumers are more likely to purchase their tomatoes at the weekly market, followed by extrinsic-sensitive consumers ( $p$-value is significant at a level of 0.01). Lastly, the extrinsic-sensitive consumers most highly valued the tomato taste, followed by intrinsic-sensitive and price-sensitive consumers. Based on our results, the three classes differed significantly at a level of 0.05 .

\section{Study limitations and future research}

One limitation of our study is that the sample was not representative in its characteristics to resemble the German population. Our sample was biased, as we only analysed young consumers and did not include consumers aged older than 30 years; most of the consumers were single. Moreover, we did not ask the respondents about their living situation. Therefore, further studies should consider using a representative sample to draw general conclusions regarding the entire population of the country. Another limitation might be that this was an online choice-experiment and not a tomato tasting, and therefore, the results are based on prior experience of the respondents. Lastly, a fair trade label was included in the choice-experiment, but all tomatoes had Germany as country of origin, although on the German market, the only fair trade tomatoes are from Morocco. Additionally, it would be interesting to include the clustering variable "growing their own tomatoes" in the questionnaire.

\section{Conclusions}

This study identified consumer classes and their preferences for fresh tomato attributes such as colour, consistency and price. We identified three types of young tomato consumers, namely price-sensitive consumers, extrinsic-sensitive consumers and intrinsic-sensitive consumers. All three classes valued different tomato attributes, which influenced their purchasing behaviour. This information is important as a base for tomato growers, breeders, and marketing practitioners.

Additionally, our results point to the necessity of targeting tomato varieties to different segments to meet the demands of the consumers. Only consumers who are satisfied with the tomato will repurchase the specific tomato variety. Against this background, it is crucial to clearly communicate the differences among the individual tomato varieties to the consumer, e.g., through sensory marketing.

\section{Acknowledgments}

This research was funded by the Ministry for Science and Culture of Lower Saxony in Germany (MWK). Many thanks, Inga Smit, for helping us in determining suitable tomato attributes.

\section{References}

Adeoye, I.B., Adegbite, O.O., Fashogbon, A.E., and Layade, A.A. (2015). Consumer purchasing behavior for tomatoes. Intl. J. Vegetable Sci. 22(3), 259-265. https://doi.org/10.1080/19315260.2015.1028695.
Auspurg, K., and Liebe, U. (2011). Choice-Experimente und die Messung von Handlungsentscheidungen in der Soziologie (Choiceexperiments and the evaluation of the choices of action in sociology). Kölner Z. für Soziologie und Sozialpsychologie 63(2), 301-314. https://doi.org/10.1007/s11577-011-0136-3.

Carroll, K.A., Bernard, J.C., and Resek, J.D. (2013). Consumer preferences for tomatoes: the influence of local, organic, and state program promotions by purchasing venue. J. Agric. Resource Econ. 38(3), 379-396.

Causse, M., Buret, M., Robini, K., and Verschave, P. (2003). Inheritance of nutritional and sensory quality traits in fresh market tomato and relation to consumer preferences. J. Food Sci. 68(7), 2342-2350. https://doi.org/10.1111/j.1365-2621.2003.tb05770.x.

Causse, M., Friguet, C., Coiret, C., Lepicier, M., Navez, B., Lee, M., and Grandillo, S. (2010). Consumer preferences for fresh tomato at the European scale: A common segmentation on taste and firmness. J. Food Sci. 75(9), S531-541. https://doi.org/10.1111/j.17503841.2010.01841.x.

Fernqvist, F., and Hunter, E. (2012). Who's to blame for tasteless tomatoes? The effect of tomato chilling on consumers' taste perceptions. Eur. J. Hortic. Sci. 77(5), 193-198.

Field, A. (2011). Discovering Statistics using SPSS: (and sex and drugs and rock 'n' roll), $3^{\text {rd }}$ edn., reprinted (Los Angeles, Calif.: Sage). http://www.uk.sagepub.com/field3e/main.htm.

Greene, W.H., and Hensher, D.A. (2003). A latent class model for discrete choice analysis: Contrasts with mixed logit. Transportation Res. Part B: Methodological, 37(8), 681-698. https://doi. org/10.1016/S0191-2615(02)00046-2.

Hongsoongnern, P. (2007). Understanding the sensory characteristics of fresh and processed tomatoes using descriptive sensory analysis. Ph.D. thesis (Kansas State University). http://hdl. handle.net/2097/261.

Keller, M., Halkier, B., Wilska, T.A., and Truninger, M. (2017). Routledge Handbook on Consumption (Taylor \& Francis). https:// doi.org/10.4324/9781315675015.

Lancaster, K.J. (1966). A new approach to consumer theory. J. Political Econ. 74, 132-157. https://doi.org/10.1086/259131.

Meyerding, S.G.H. (2016). Consumer preferences for food labels on tomatoes in Germany - A comparison of a quasi-experiment and two stated preference approaches. Appetite 103, 105-112. https://doi. org/10.1016/j.appet.2016.03.025

Oltman, A.E., Jervis, S.M., and Drake, M.A. (2014). Consumer attitudes and preferences for fresh market tomatoes. J. Food Sci. 79(10), 2091-2097. https://doi.org/10.1111/1750-3841.12638.

Oltman, A.E., Yates, M.D., and Drake, M.A. (2016). Preference mapping of fresh tomatoes across 3 stages of consumption. J. Food Sci. 81(6), 1495-1505. https://doi.org/10.1111/1750-3841.13306.

Pagliarini, E., Monteleone, E., and Ratti, S. (2001). Sensory profiles of eight tomato cultivars (Lycopersicon esculentum) and its relationship to consumer preference. Italian J. Food Sci. 13(3), 285-296.

Sinesio, F., Cammareri, M., Moneta, E., Navez, B., Peparaio, M., Causse, M., and Grandillo, S. (2010). Sensory quality of fresh French and Dutch market tomatoes: A preference mapping study with Italian consumers. J. Food Sci. 75(1), 55-67. https://doi.org/10.1111/ j.1750-3841.2009.01424.x

Sinesio, F., Moneta, E., and Peparaio, M. (2007). Sensory characteristics of traditional field grown tomato genotypes in southern Italy. J. Food Quality 30, 878-895. https://doi.org/10.1111/j.17454557.2007.00161.x. 
Skreli, E., and Imami, D. (2012). Analyzing consumers' preferences for apple attributes in Tirana, Albania. Intl. Food and Agribusiness Mgt. Rev. 15(4), 137-156.

Thøgersen, J. (2017). Sustainable food consumption in the nexus between national context and private lifestyle: A multi-level study. Food Quality and Preference 55, 16-25. https://doi.org/10.1016/j. foodqual.2016.08.006.

Received: Feb. 2, 2018

Accepted: Jul. 22, 2019

Address of authors:

Kristin Jürkenbeck* and Stephan G.H. Meyerding University of Göttingen, Department of Agricultural Economics and Rural Development, Marketing of Food and Agricultural Products, Platz der Göttinger Sieben 5, 37073 Göttingen, Germany

* Corresponding author;

E-mail: kristin.juerkenbeck@uni-goettingen.de

Tel.: +49 (0) 551 39-26245; Fax: +49 (0) 551 39-26242 